\title{
Simulasi Penjalaran Gelombang Tsunami di Pesisir Pantai Utara Pulau Halmahera
}

\author{
Fanya Sankoya, Guntur Pasaua*, Gerald Tamuntuana*, \\ aJurusan Fisika, FMIPA, Unsrat, Manado \\ KATA KUNCI \\ A B S T R A K
}

Tsunami, Gempa Bumi,

Simulasi Tsunami, Sesar

\begin{abstract}
Telah dilakukan simulasi penjalaran gelombang tsunami di pesisir pantai utara pulau Halmahera. Lokasi penelitian berada pada kooordinat $1^{\circ}-3^{\circ}$ LU dan $127^{\circ}-129^{\circ}$ BT. Metode penelitian meliputi: mengumpulkan data gempa tektonik dari NOAA, melakukan perhitungan panjang patahan, lebar patahan, dan deformasi dasar laut, melakukan simulasi dengan software WinITDB. Hasil simulasi dalam bentuk grafik tinggi gelombang dan waktu tiba gelombang tsunami. Dari hasil simulasi yang telah dilakukan, salah satu wilayah yang masuk dalam klasifikasi sangat berbahaya adalah Wayamli karena tinggi maksimum gelombang tsunami $\geq 3 \mathrm{~m}$.

A B S T R A C T

A simulation of tsunami wave transmission on the north coast of Halmahera Island has been done. The research coordiantes are at $1^{\circ}-3^{\circ}$ north latitude and $127^{\circ}-129^{\circ}$ east longitude. Research method covers these: collecting tectonic earthquake data from NOAA, calculating the length and width of the fracture and the seafloor deformation, and carrying the simulation out using winTDB software. The simulation result is presented in the form of maximum height graph and arrival time of tsunami wave. According to the simulation's result that has been done, one of the regions that classified as highly-dangerous is Wayamli, since its maximum waveheight is $\geq 3 \mathrm{~m}$
\end{abstract}

K E Y W O R D S

Tsunami, Earthquake,

Tsunami Simulation, Fault
TERSEDIAONLINE

1 Februari 2017

\section{Pendahuluan}

Provinsi Maluku Utara merupakan daerah tektonik yang kompleks, karena ada interaksi antara lempeng Pasifik di timur, lempeng Eurasia di barat, lempeng Filipina di utara, dan lempeng IndoAustralia di selatan. Ketiga lempeng tektonik ini bergerak dengan arah dan kecepatan yang berbedabeda, sehingga mengakibatkan struktur patahan yang memicu terjadinya aktivitas gempa bumi tektonik yang dapat menyebabkan tsunami (Retnowati, 2008). Berdasarkan data NOAA daerah Maluku Utara pernah terjadi gempabumi yang menyebabkan tsunami yaitu pada tahun 1994 dengan kekuatan 7,0 SR dan ketinggian air 2,00 meter, tahun 1998 dengan kekuatan 7,7 SR dan ketinggian air 2,75 meter, tahun 2014 dengan kekuatan 7,1 SR dan ketinggian air 3,09 meter.
Data historis terjadinya tsunami secara luas digunakan untuk penetapan tingkat risiko bahaya tsunami, juga dapat menjadi suatu dasar atau acuan bagi pemerintah daerah untuk mengembangkan pembangunan di wilayah pesisir (Gusiakov, 2005). Oleh karena itu, studi ini akan dilakukan simulasi gelombang tsunami dengan menggunakan software WinITDB untuk mengetahui secara spesifik daerah mana yang rentan dengan tsunami.

\section{Tektonik Maluku Utara}

Secara tektonik wilayah ini dipengaruhi oleh subduksi lempeng Filipina di utara hingga ke timur, sesar Sorong dan Sula di selatan, dan subduksi ganda lempeng Laut Maluku di sebelah barat (Tim Revisi Peta Gempa 2010). Daerah ini juga berada di pinggiran lempeng aktif. Hal ini dapat ditunjukkan dengan adanya gempa-gempa tektonik yang pernah terjadi. Berdasarkan data yang diambil dari NOAA,

*Corresponding author: Jurusan Fisika FMIPA UNSRAT, Jl. Kampus Unsrat, Manado, Indonesia 95115; Email address: fanyasangkoy@gmail.com

Published by FMIPA UNSRAT (2017) 
pusat gempabumi tektonik yang terjadi di daerah ini berada di dasar laut. Khususnya wilayah yang berada di pesisir Pantai Utara Halmahera, karena berhadapan langsung dengan lempeng Pasifik. Wilayah ini juga masuk dalam aktifitas cincin api Pasific (Pasific Ring of Fire) sehingga menyebabkan daerah ini rentan dengan tsunami.

\section{Gelombang Mekanik}

Gelombang mekanik memiliki cepat rambat sebanding dengan kerapatan medium rambatannya, oleh karena itu cepat rambat dalam zat cair lebih besar dibanding dalam gas (Geoberman, 1988). Gelombang air laut adalah suatu pergerakan gelombang yang menimbulkan perubahan pada gerakan naik dan turunnya air pada lapisan permukaan maupun di bawah permukan laut yang membentuk grafik sinusoida. Ketika gelombang menjalar dari suatu tempat yang sangat dalam menuju ke tempat yang semakin dangkal, maka pada suatu tempat tertentu gelombang tersebut akan pecah dan dihempaskan ke pantai dalam bentuk hempasan gelombang. Demikian juga dengan gelombang tsunami, pada saat memasuki perairan yang dangkal maka tinggi gelombang tsunami meningkat dan kecepatan gelombang menurun tetapi energinya masih sangat kuat sehingga mampu menghanyutkan apapun yang dilaluinya (Sugito, 2008).

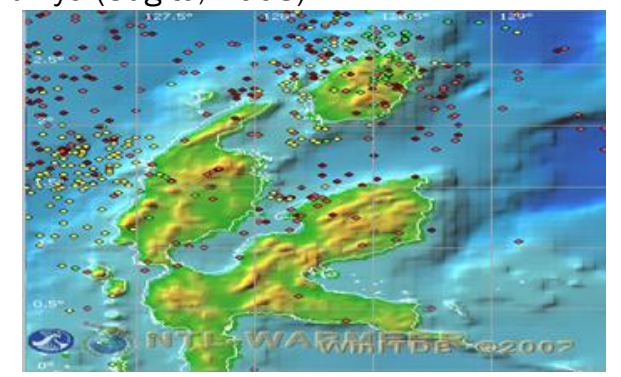

Gambar 1. Peta tektonik Maluku Utara

\section{Tsunami}

Tsunami adalah serangkaian gelombang yang menjalar dengan kecepatan hingga $900 \mathrm{~km}$ per jam, terutama diakibatkan oleh gempabumi yang terjadi di dasar laut. Sedangkan menurut Gross (1993) gelombang merupakan gangguan yang terjadi di permukaan air laut. Oleh karena itu Duddley dan Lee (2006) mendefinisikan tsunami sebagai rangkaian gelombang yang umumnya sering diakibatkan oleh gerakan-gerakan besar di dasar laut.

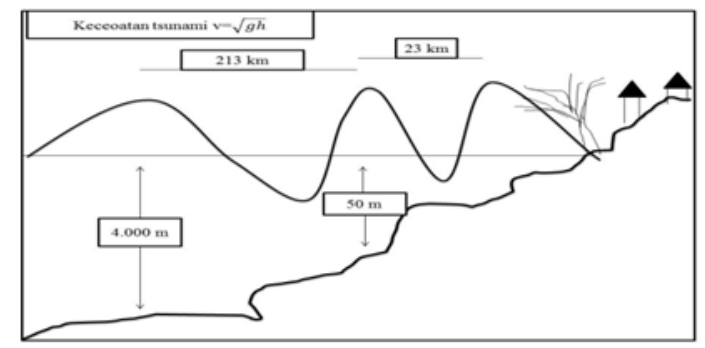

Gambar 2. Proses terjadinya tsunami
Gelombang tsunami bergerak dengan kecepatan yang setara dengan akar kuadrat hasil perkalian antara percepatan grafitasi dan kedalaman air laut.

Dimana:

$$
v=\sqrt{g h}
$$

dengan:

$v=$ Kecepatan rambat tsunami $(\mathrm{m} / \mathrm{s})$

$g=$ Percepatan grafitasi $\left(\left(\mathrm{m} / \mathrm{s}^{2}\right)\right.$

$h=$ Kedalaman laut $(\mathrm{m})$

(Eze et al., 2009).

Kecepatan gelombang tsunami untuk setiap kedalaman laut berbeda-beda (Sutrisno, 2007). Semakin mendekati pantai kecepatan gelombangnya berubah dari $v(x)_{0}$, $v(x)_{1}, v(x)_{2}, v(x)_{3}, \ldots, v(x)_{n}$ sedangkan waktu tiba (t) gelombang tsunami dapat dihitung dengan memperhatikan perubahan kedalaman laut yang dilewati (semakin dangkal saat mendekati pantai). Kondisi seperti ini dapat diselesaikan dengan cara membagi panjang lintasan $x$ kedalaman elemen panjang $d x_{i}$ (dengan asumsi pada jarak $d x_{i}$ kedalaman lautnya tetap). Jika $d x_{i}=d x$ maka waktu tiba gelombang tsunami dapat dihitung dengan persamaan berikut:

$\sum_{i=1}^{n} t=\int_{0}^{x_{1}} \frac{d x}{v(x)_{1}}+\int_{0}^{x_{2}} \frac{d x}{v(x)_{2}}+\int_{0}^{x_{3}} \frac{d x}{v(x)_{3}}+. .+\int_{0}^{x_{n}} \frac{d x}{v(x)_{n}}(2.2)$ dengan :

$\mathrm{t} \quad=$ waktu tiba gelombang tsunami (s)

$\mathrm{dx}=$ jarak setiap titik lintasan $(\mathrm{m})$

$\mathrm{v}(\mathrm{x})=$ kecepatan tsunami disetiap posisi $(\mathrm{m} / \mathrm{s})$

(WinITDB, 2007)

Jika membandingkan hubungan setiap variabel kecepatan rambat energi mekanik dengan kecepatan dan arah rambat gelombang tsunami di setiap kedalaman yang berbeda, maka tinggi gelombang tsunami dapat dihitung dengan persamaan berikut:

$$
H_{n}=\sqrt[4]{\frac{v_{n-1}}{v_{n}}} \sqrt{\frac{b_{n-1}}{b_{n}}} H_{n-1} \cdots \cdots
$$$$
\text { Wells dan Copersmith }
$$
panjang patahan, lebar patahan dan pergeseran tanah untuk patahan naik dengan menggunakan hubungan dari magnitudo gempa yaitu:

$$
\begin{aligned}
& \log (L)=0,63 M-2,86 \\
& \log (W)=0,41 M-1,61 \\
& \log (D)=0,29 M-1,84
\end{aligned}
$$

dengan:

$$
\begin{array}{ll}
\mathrm{M} & =\text { Magnitudo gempabumi (SR) } \\
\mathrm{L} & =\text { Surface rupture length/ panjang patahan } \\
& (\mathrm{km}) \\
\mathrm{W} & =\text { Rupture width/ lebar patahan }(\mathrm{km}) \\
\mathrm{D} & =\quad \text { Maximum displacement/ pergeseran } \\
& \operatorname{tanah~}(\mathrm{m})
\end{array}
$$


Menurut Lautrup (2005), pada saat terjadi tsunami, seluruh kolom air yang berada diatas patahan akan terdorong bersama patahan naik, sehingga volume kolom air yang terdorong keatas sama dengan volume patahan naik yaitu perkalian antara panjang patahan (L), lebar patahan (W), dan deformasi dasar laut (D). Sehingga massa air (Ma) gelombang tsunami adalah :

$$
m_{a}=\rho L W D
$$

dengan :

$$
\begin{array}{ll}
L & =\text { panjang patahan }(\mathrm{m}) \\
W & =\text { lebar patahan }(\mathrm{m}) \\
D & =\text { deformasi dasar laut }(\mathrm{m}) \\
\rho & =\text { massa jenis air }\left(\mathrm{kg} / \mathrm{m}^{3}\right) \\
m_{a} & =\text { massa air }(\mathrm{kg})
\end{array}
$$

Sedangkan volume massa air yang terangkat dari titik kesetimbangan adalah $V=L W D$. Massa airnya adalah $\mathrm{M}=\rho V=\rho L W D$. Apabila tinggi ratarata setiap partikel air yang terdorong oleh gerakan patahan naik sebesar D/2, maka besar selisih energi potensial adalah:

$$
E=M g \frac{1}{2} \mathrm{D}=\frac{1}{2} \rho L W g D^{2}
$$

dengan:

$$
\begin{array}{ll}
E & =\text { energi potensial air (joule) } \\
M & =\text { massa air }(\mathrm{kg}) \\
g & =\text { grafitasi }\left(\mathrm{m} / \mathrm{s}^{2}\right) \\
D & =\text { deformasi dasar laut }(\mathrm{m}) \\
\rho & =\text { massa jenis air }(\mathrm{kg} / \mathrm{m}) \\
L & =\text { panjang patahan }(\mathrm{m}) \\
W & =\text { lebar patahan }(\mathrm{m})
\end{array}
$$

(Lautrup, 2005).

Menurut Rahmawan (2012), terdapat lima macam klasifikasi tsunami berdasarkan tinggi gelombangnya, yaitu:

Tabel 1. Klasifikasi bahaya gelombang tsunami berdasarkan tinggi gelombang

\begin{tabular}{|c|c|c|}
\hline No & Tinggi Tsunami & Klasifikasi \\
\hline 1 & $\mathrm{H} \geq 3 \mathrm{~m}$ & Sangat Bahaya \\
\hline 2 & $1,5 \mathrm{~m} \leq \mathrm{H}<3 \mathrm{~m}$ & Bahaya \\
\hline 3 & $0,5 \mathrm{~m} \leq \mathrm{H}<1,5 \mathrm{~m}$ & Cukup Bahaya \\
\hline 4 & $\mathrm{H}<0,5 \mathrm{~m}$ & Tidak Bahaya \\
\hline
\end{tabular}

\section{Material dan Metode}

Penelitian ini dilakukan dengan menggunakan software WinITDB. Data yang diambil dari NOAA merupakan data gempa bumi tektonik yang menyebabkan tsunami pada periode tahun 18902016. Wilayah yang diteliti adalah wilayah yang berada dipesisir pantai Pulau Halmahera $\left(3^{\circ} \mathrm{LU}-3^{\circ}\right.$ LS) dan $\left(124^{\circ}-129^{\circ}\right.$ BT).

Penelitian ini diawali dengan memilih lokasi yang penduduknya padat sesuai dengan data statistik daerah Pulau Halmahera, kemudian diplot sebagai titik yang akan diterjang tsunami pada software. Kemudian memasukkan data historis dari NOAA kedalam software. Selanjutnya melakukan perhitungan panjang patahan, lebar patahan, dan deformasi dasar laut secara manual berdasarkan persamaan (2.4),(2.5),(2.6). Melakukan simulasi dengan software untuk menghasilkan tinggi maksimum dan waktu tiba gelombang tsunami. Dengan memasukkan posisi lintang sumber tsunami, posisi bujur sumber tsunami, posisi lintang daerah yang akan diterjang tsunami, posisi bujur daerah yang akan diterjang tsunami, panjang patahan, lebar patahan, deformasi dasar laut, dan waktu maksimum penjalaran gelombang tsunami.

\section{Hasil dan Pembahasan}

Berdasarkan data NOAA periode tahun 1890-2016, ada 4 data yang pusatnya di Maluku Utara dan menyebabkan tsunami. Hasil simulasi dibahas berdasarkan 4 skenario tsunami yaitu skenario a, skenario b, skenario c, skenario d. Simulasi penjalaran gelombang dari masing-masing skenario dapat dilihat pada gambar 3, gambar 5, gambar 7, dan gambar 9 . Sedangkan grafik hasil simulasi dapat dilihat pada gambar 4, gambar 6, gambar 8, dan gambar 10.

\section{Skenario $\mathrm{A}$}
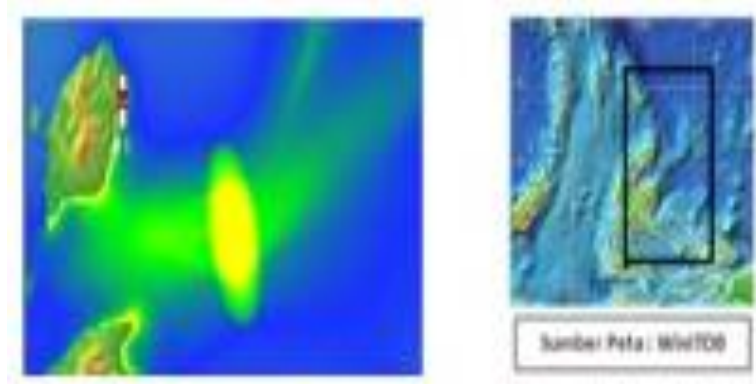

Gambar 3. Simulasi penjalaran gelombang tsunami

Skenario tsunami A adalah tsunami yang terjadi akibat adanya gempabumi yang menyebabkan tsunami dengan magnitudo 7,0 SR yang berada pada koordinat 2,64 LU dan 129,25 BT. Tsunami yang terjadi pada peristiwa ini memiliki panjang patahan $35,48 \mathrm{~km}$, lebar patahan $18,19 \mathrm{~km}$, dan deformasi patahan $1,54 \mathrm{~m}$ dengan energi sebesar 7,77 J. Tinggi maksimum gelombang tsunami pada skenario ini, berada di wilayah Bere-bere dengan tinggi $0,7 \mathrm{~m}$ pada menit ke-18. Hasil dari simulasi ditampilkan pada gambar berikut:

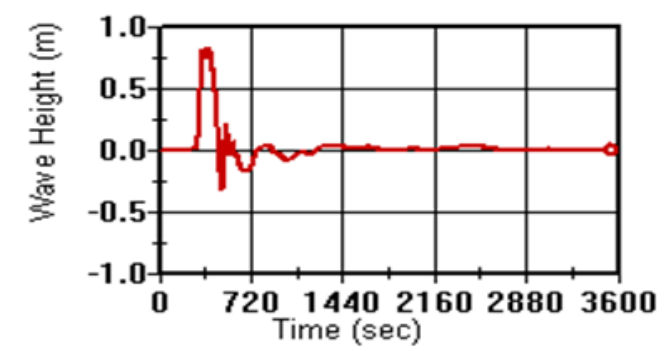

Gambar 4. Grafik tinggi gelombang dan waktu tiba gelombang tsunami 


\section{Skenario B}
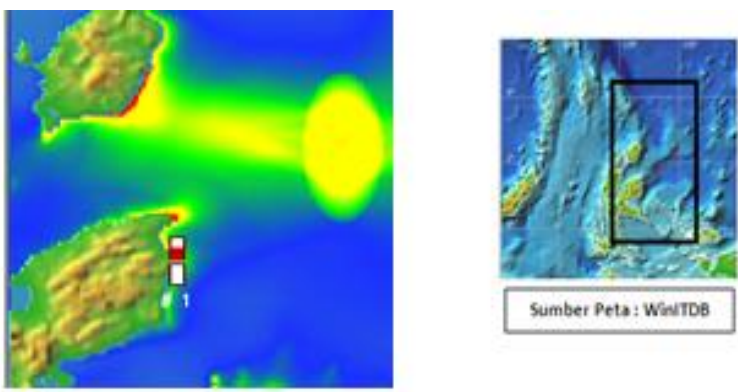

Gambar 5. Simulasi Penjalaran Gelombang Tsunami

Skenario tsunami B merupakan peristiwa tsunami yang diakibatkan oleh gempabumi yang mengakibatkan tsunami dengan magnitudo $7,1 \mathrm{SR}$ yang berada pada koordinat 1,80 LU dan 129,48 BT. Pada peristiwa ini tsunami yang terjadi memiliki panjang patahan $41,02 \mathrm{~km}$, lebar patahan 19,99 $\mathrm{km}$, dan deformasi dasar laut 1,65 $\mathrm{m}$ dengan energi sebesar 11,29 J. Tinggi maksimum gelombang tsunami pada skenario ini, berada di wilayah Berebere dengan tinggi $0,7 \mathrm{~m}$ pada menit ke-21. Hasil dari simulasi ditampilkan pada gambar berikut:

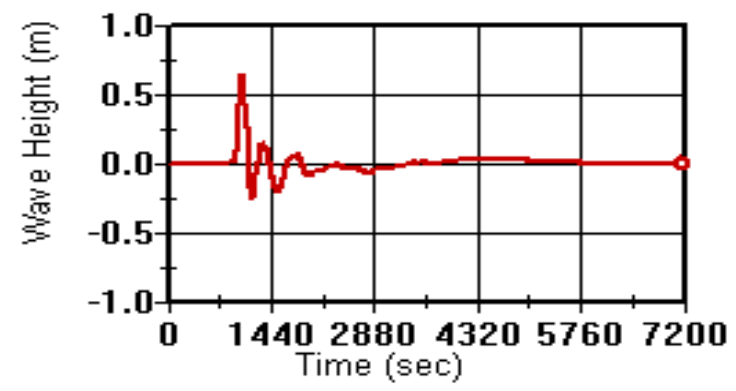

Gambar 6. Grafik tinggi gelombang dan waktu tiba gelombang tsunami

\section{Skenario $\mathrm{C}$}
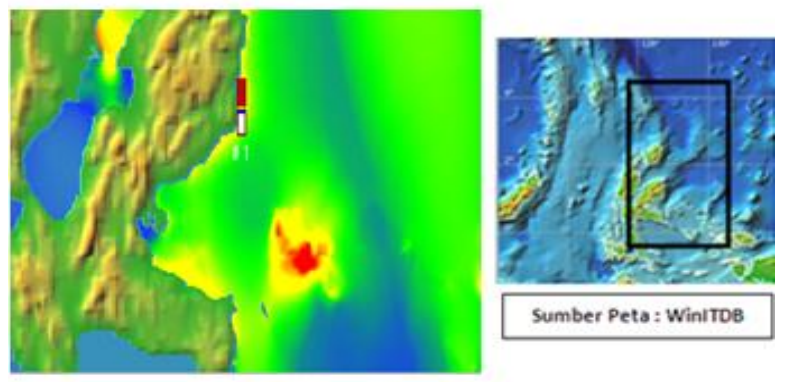

Gambar 7. Simulasi Penjalaran Gelombang Tsunami

Skenario tsunami C adalah peristiwa tsunami yang diakibatkan oleh gempabumi yang menyebabkan tsunami dengan magnitudo $7,7 \mathrm{SR}$ yang berada pada koordinat 2,09 LU dan 129,37 BT. Tsunami yang terjadi pada peristiwa ini memiliki panjang patahan $97,94 \mathrm{~km}$, lebar patahan 35,23 $\mathrm{km}$, dan deformasi dasar laut 2,47 $\mathrm{m}$ dengan energi sebesar 25,17 J. Tinggi maksimum gelombang tsunami pada skenario ini, berada di wilayah Berebere dengan tinggi $1,9 \mathrm{~m}$ pada menit ke-15. Hasil dari simulasi ditampilkan pada gambar berikut:

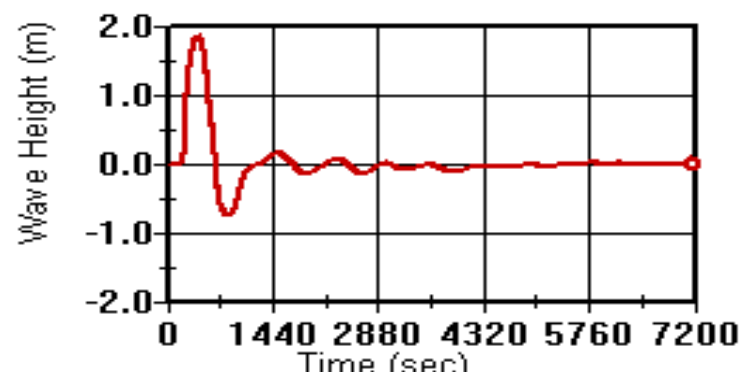

Gambar 8. Grafik Tinggi dan waktu tiba gelombang tsunami

\section{Skenario D}
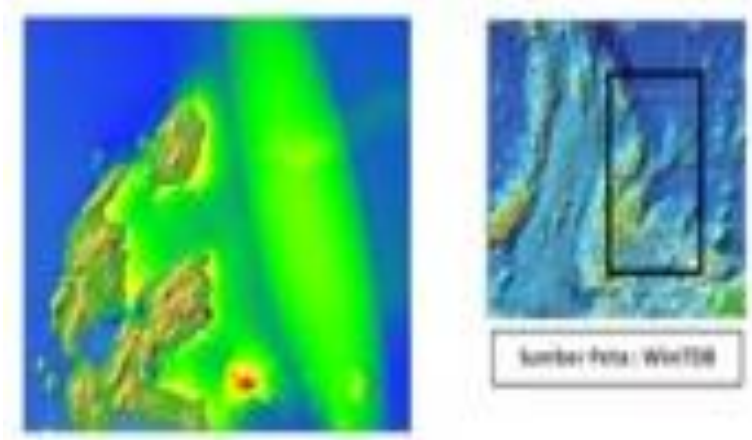

Gambar 9. Simulasi Penjalaran Gelombang Tsunami

Pada peristiwa ini tsunami yang terjadi adalah akibat sumber gempa berkekuatan 9,0 SR yang berada pada koordinat 1,8092 LU dan 129,4817 BT. Tsunami yang terjadi memiliki panjang patahan $645,65422 \mathrm{~km}$, lebar patahan $120,22644 \mathrm{~km}$, deformasi dasar laut 5,88843 $\mathrm{m}$ dengan energi sebesar 142,862 J. Tinggi maksimum gelombang tsunami pada skenario ini, berada di wilayah Wayamli dengan tinggi $6,1 \mathrm{~m}$ pada menit ke-19. Hasil dari simulasi ditampilkan pada gambar berikut:

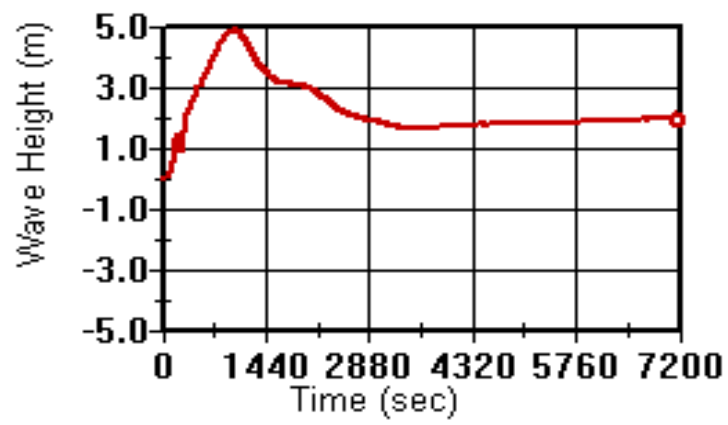

Gambar 10. Grafik tinggi gelombang dan waktu tiba gelombang tsunami

Area penyerapan ikatan selulosa $\beta$-glycosidic tampak pada bilangan gelombang $829,10 \mathrm{~cm}^{-1}$ dan $902,14 \mathrm{~cm}^{-1}$. Serapan ikatan ini akan tampak pada bilangan gelombang 950- $800 \mathrm{~cm}^{-1}$ (Kumar dkk., 2014) atau $897 \mathrm{~cm}^{-1}$ (Nomanbhay dkk., 2013). Pita spektral $898 \mathrm{~cm}^{-1}$ disebut juga pita penyerapan amorf (Ciolacu dkk., 2011). Serapan gugus C-H aromatik terbaca pada daerah bilangan gelombang 695,39 cm-1; 856,23 cm-1 dan 897,12 cm-1 (Silverstein dkk., 1991). 


\begin{abstract}
4. Kesimpulan
Pretreatment dengan gelombang mikro (microwave) kepada serbuk kayu cempaka (Elmerillia ovalis) pada daya (P) 300 watt dan suhu (T) 40 menit telah menyebabkan perubahan karakterisasi sifat fisik serbuk kayu cempaka.

Hasil karakterisasi dengan X-Ray Diffraction memperlihatkan telah terjadi penurunan kristalinitas dari $61,75 \%$ (non pretreatment) menjadi 56,35\% (pretreatment). Struktur kristal pada puncak tertinggi pada intensitas 353 di sudut $2 \theta$ pada titik 22,41 dan struktur non-cristal (amorf) pada intensitas 135 di sudut $2 \theta$ pada titik 18,89 untuk non-pretreatment. Penurunan struktur kristal pada intensitas sebesar 307 di sudut $2 \theta$ pada titik 21,85 dan struktur non-cristal pada intensitas 134 pada sudut $2 \theta 19,89$ untuk pretreatment.
\end{abstract}

Analisis karakterisasi berdasarkan SEM menunjukkan bahwa iradiasi gelombang mikro telah menyebabkan perubahan morfologi permukaan serbuk kayu cempaka. Permukaan serbuk kayu berhasil bertransformasi menjadi lebih berongga dan bertekstur setelah dilakukan pretreatment dengan microwave.

Analisis spektra FT-IR menunjukkan bahwa pretreatment microwave belum memperlihatkan perubahan gugus-gugus fungsional dibandingkan dengan non pretreatment. Kesamaan gugus-gugus fungsi tampak pada serapan lebar $3200-3500 \mathrm{~cm}^{-1}$ $(\mathrm{OH})$ pada selulosa, $2900-2910 \mathrm{~cm}^{-1}(\mathrm{CH})$, sekitar $1700 \mathrm{~cm}^{-1}(\mathrm{C}=0), 1365-1370 \mathrm{~cm}^{-1}(\mathrm{C}-\mathrm{H}$ selulosa dan hemiselulosa), 1124-1260 $\mathrm{cm}^{-1}$ (C-O-C), 829-902 $\mathrm{cm}^{-1}$ (ß-glycosidic) dan 670-695 $\mathrm{cm}^{-1}$ (C-H cincin aromatik).

\section{Daftar Pustaka}

Ahyar, A. 2014. Bioethanol Production from cellulose in red algae Gracilaria verrucosa by separated hydrolysis and fermentation system using trichoderma viride and zymomonaz mobilis. International Journal of Phasrma and Bio Sciences.5(2):445- 452.

Balat, M., H. Balat dan C. Oz. 2009.Progress in bioethanol processing.Progr.Energy Combust. Sci. 34 (5):551-573.

Billmeyer, F.W.1996. Textbook of Polymer Science.Edisi ke-3. New York: John Wiley and Sons.

Callister, W.D. 2007.Materials Science and Engineering: An Introduction. John Wiley \& Sons, Inc. New York.

Campbel,T. C.\& R.G.Fuller. 1978. Study Guide to accompany Physics Including Human Applications. New York: Harper \& Row, Publishers.

Creswell, C.J. et al. 2005. Analisa Spektrum Senyawa Organik. Cetakan ke-10.Edisi ketiga.Penerjemah Kosasih Padmawinata dan Iwang Soediro.Penerbit ITB. Halaman :1-100. Bandung.
Day, R.A. \& A.L. Underwood. 2001. Analisis Kimia Kuantitatif. Terjemahan I.Sopyan. Edisi ke-5. Jakarta: Penerbit Erlangga.

Fan, M., D. Dai \& B. Huang. 2012. Fourier Transform Infrared Spectroscopy for Natural Fibres.In Fourier Transform - Materials Analysis. Salih Salih (Ed.). Intech.

http://www.intechopen.com/books/fouriertransform-materials-analysis/fourier-transforminfraredspectroscopy-for-natural-fibres. 45-68 pp. [3 Februari 2017].

Fatriasari, W., W.Syafii, N. Wistara, K.Syamsul dan B.Prasetya. 2016. Lignin and cellulose changes of betung bamboo (Dendrocalamus asper) pretreated microwave heating. International Journal on Advanced Science Engineering Information Technology.6(2): 186-195.

Fatriasari, W \& E. Hermiati. 2016. Lignocellulosic biomass for bioproduct: its potency and technology development: A Review. J. Lignocellulose Technol. 1:1-14.

Galbe, M dan G. Zachii. 2007. Pre-treatment of Lignocellulosic Materials forEfficient Bioethanol Production. Biofuels.Advancesin Biochemical Engineering/Biotechnology 108:41-65 .

Giancoli, D.C. 2001. Fisika.Jilid 2.Edisi ke-5. Jakarta. Penerbit Perlangga.

Hua, Z. L. Cecil, G. Jones, A. Baker, X. Shuqian, O. Olarongbe dan V.N. Person. 2009. Regenerating cellulose from ionic liquids for an accelerated enzymatic hydrolysis. Journal of Biotechnology139: 47-54.

Husnil, Y.A. 2009.Perlakuan Gelombang Mikro dan Hidrolis Enzimatik pada Bambu untuk Pembuatan Bioetanol.[Tesis]. Universitas Indonesia.Depok

Kinney, T.J., C.A. Masiello, B. Dugan, W.C. Hockaday, M.R. Dean, K. Zygourakis dan R.T. Barnes. 2012. Hydrologic properties of biochars produced at different temperatures. Biomass and Bioenergy.30: 1-10.

Kumar, A., Y. S. Negi, V.Choudhary \& N. K.Bhardwaj. 2014. Characterization of Cellulose Nanocrystals Produced by Acid-Hydrolysis from Sugarcane Bagasse as Agro-Waste .Journal of Materials Physics and Chemistry.2 (1): 1-8.

Li, Q., Y-C.He, M. Xian, G.Jun, X. Xu, J-M. Yang, dan L-Z. Li. 2009.Improving enzymatic hydrolysis of wheat straw using ionic liquid 1-ethyl methylimidazolium diethyl phosphate pretreatment. Bioresource Technology100:3570-3575.

Lionetto, F. R.D. Sole, Cannoletta, D. Vasapollo, G. Maffezzoli, A. 2012. Monitoring Wood Degradation during Weathering by Cellulose Crystallinity.Materials 5:1910-1922.

Mortimer, R.G. 1993. Physical Chemistry. Redwood City: The Benjamin/Cummings Publishing Company, Inc.

Nomanbhay, S.M., R. Hussain \& K.Palanisamy. 2013. Microwave-Assisted alkaline pretreatment and microwave assisted 
enzymatic saccharification of oil palm empty fruit bunch fiber for enhanced fermentable sugar yield. Journal of Sustainable Bioenergy Systems.3: 7-17.

Park, S. Baker, J.O. Himmel, M.E. Parilla, P.A. Johnson,D.K. 2010. Cellulose Crystallinity Index: Measurement Techniques and Their Impact onlnterpreting Cellulose Performance. Biotechnology for Biofuels. 10.1186/17546834-3-10

Sangian, H.F., J. Kristian, S.Rahma, H.K.Dewi, D.A..Puspasari, S.Y.Agnesty, S.Gunawan dan A. Widjaja. 2015a. Preparation of reducing sugar hydrolyzed from high-lignin coconut coir dust pretreated by the recycled ionic liquid [mmim][dmp] and combination with alkaline.Bulletin of Chemical Reaction Engineering \& Catalysis.10 (1): 8-22.

Sangian, H.F., J. Kristian, S.Rahma, S.Y.Agnesty, S.Gunawan dan A. Widjaja. 2015b. Comparative Study of the Preparation of Reducing Sugars Hydrolyzed from HighLignin Lignocellulose Pretreated with Ionic Liquid, Alkaline Solution and Their Combination. J. Eng. Technol. Sci.47 (2): 137148

Sangian, H.F., D. Ranggina., G.M.Ginting., AA. Purba.,S. Gunawan., A. Widjaya. 2015. Study of the Preparation of Sugar from High-Lignin Lignocellulose Applying Subcritical Water and Enzymatic Hydrolysis: Synthesis and Consumable Cost Evaluation. Scientific study\& Research Chemistry \& Chemical Engineering, Biotechnology, Food Industry. 16(1):013-027.

Sangian, H.F. 2016. Analysis of retention time and substances released enzymatically fromlignocellulose, coconut coir treated by alkaline, ionic liquid [mmim] $[\mathrm{dmp}]$ and combined method by observing the HPLC-RI spectra. International Journal of ChemTech Research.9(12):715-724.

Sasmuko S.2010. Wood properties of local species for wooden house of woloan in north Celebes Province.

Setiawan, D.A., Argo, B.D., Hendrawan, Y., 2015. Pengaruh konsentrasi dan preparasi membran terhadap karakterisasi membran kitosan. Jurnal keteknikan pertanian tropis dan biosistem.3:(1) : 95-99

Simbar M, M Theodora. Katiandagho, Lolowang T.F., Baroleh J. 2014. Analisis Pengendalian Persediaan Bahan Baku Cempaka pada Industri Mebel dengan menggunakan metode EOQ (Studi Kasus pada UD Batu Zaman). Cocos 5(3)

Silverstein, R. M., Bassler, G.C., \& Morril, T.C., 1991, Spectrometric Identification of Organic Coumpounds (Vol.Ed.5). Jhon Wiley \&Sons,Inc., New york.

Sukadana, Imade. 2010. Aktifitas Senyawa Flafonoid Dari Kulit Akar Awar-awar.4 (1):6367.

SurdiaN.M. 1993. Ikatan dan Struktur Molekul.Jakarta.

Van Vlack, LH. 1994. IImu dan Teknologi Bahan: IImu Logam dan Bukan logam.Terjemahan S.Djaprie. Edisi ke-5. Jakarta: Penerbit Erlangga.

Widjaja, A., S.Y.Agnesty., H.F.Sangian., dan S.Gunawan dan 2015. Application of Ionic Liquid [DMIM] DMP Pretreatment in the Hydrolysis of sugarcane Bagase for Biofuel Production.Buletin of Chemical Reaction Engineering \& Catalysis.10(1);70-77. 